Article

\title{
Investigation of Elastomer Seal Energization: Implications for Conventional and Expandable Hanger Assembly
}

\author{
Harshkumar Patel and Saeed Salehi * \\ Mewbourne School of Petroleum and Geological Engineering, University of Oklahoma, Norman, OK 73071, \\ USA; harsh@ou.edu \\ * Correspondence: salehi@ou.edu; Tel.: +1-405-325-6829
}

Received: 16 January 2019; Accepted: 22 February 2019; Published: 25 February 2019

check for updates

\begin{abstract}
Elastomer seals are extensively used in various wellhead and casing/liner hanger equipment as barriers for isolating fluids. Seal assemblies have been identified as one of the major cause of well control incidents. Majority of hangers utilize conventional weight- or mechanical-set slip-and-seal assembly. The objective of this paper is to conduct a detailed investigation of seal energization in conventional and relatively newer expandable type hanger seal assembly. To achieve the objective, the finite element modeling approach was employed. Three dimensional computer models consisting of concentric casings and annular elastomer seal element were constructed. Seal energization process was modelled by manipulating boundary conditions. Conventional seal energization was mimicked by applying rigid support at the bottom of elastomer element and compressing it from the top. Expandable hanger type seal energization was modelled by radially displacing the inner pipe to compress annular seal element. Seal quality was evaluated in terms of contact stress values and profile along the seal-pipe interface. Different amounts of seal energization were simulated. Both types of seal energization processes yielded different contact stress profiles. For the same amount of seal volumetric compression, contact stress profiles were compared. In case of conventional seal energization, contact stress profile decreases from the compression side towards support side. The seal in expandable hanger generates contact stress profile that peaks at the center of contact interface and reduces towards the ends. Convectional seal assembly has more moving parts, making it more prone to failure or under-energization. Finite Element Models were validated using analytical equations, and a good match was obtained. The majority of research related to elastomer seal is focused on material properties evaluation. Limited information is available in public domain on functional design and assessment of seal assembly. This paper adds novel information by providing detailed assessment of advantages and limitations of two different seal energization process. This opens doors for further research in functional failure modes in seal assembly.
\end{abstract}

Keywords: elastomer seal; finite element analysis; contact pressure; sensitivity analysis; well integrity; liner hanger

\section{Introduction}

Elastomer is a cross-linked network of natural or synthetic polymers. Elastomer material is relatively cheaper and exhibits characteristics property of deforming and recovering under load (elasticity and resilience). Moreover, elastomer seals are suitable for dynamic application [1] and their sealability does not depend on surface characteristic like metal-to-metal seal [2]. Because of these advantages, elastomer material is still widely used in various drilling, completion, and wellhead equipment. In addition to packers, blow-out preventers, and safety valves, elastomer seals is a critical component of casing and liner hanger assemblies. 
There are two major types of elastomer seal assembly in liner hangers-conventional and expandable. As shown in Figure 1a, conventional seal assembly is set by applying axial compression load on compression plate or cone either mechanically or hydraulically. As the load is applied, elastomer component expands radially and seals annular pressure below the hanger. Slips element has serrated teeth which engages the opposing surface when the compression is applied and keeps the seal under energization. Expandable liner hanger is a relatively newer technology which offers several operational advantages over traditional assemblies [3-7]. Expandable liner hanger consists of a smooth body with no moving parts and elastomer elements bonded to its outer profile (Figure 1b). The idea is to expand the liner either hydraulically by applying internal pressure or mechanically by running in a solid mandrel having larger outer diameter than the internal diameter of hanger. Expansion of hanger body leads elastomer elements to compress against the casing resulting in seal energization. The seals not only provide hydraulic integrity, but also act as anchor for the liner.

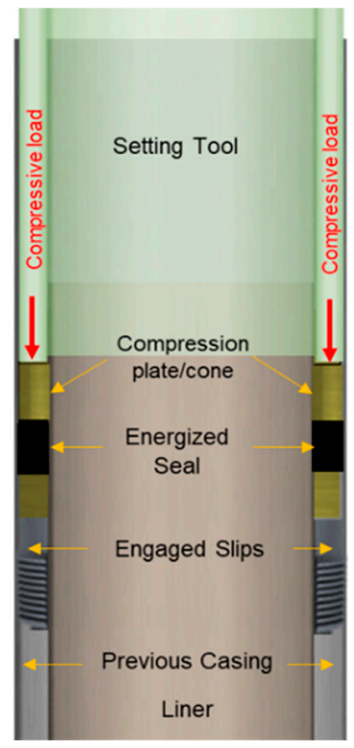

(a)

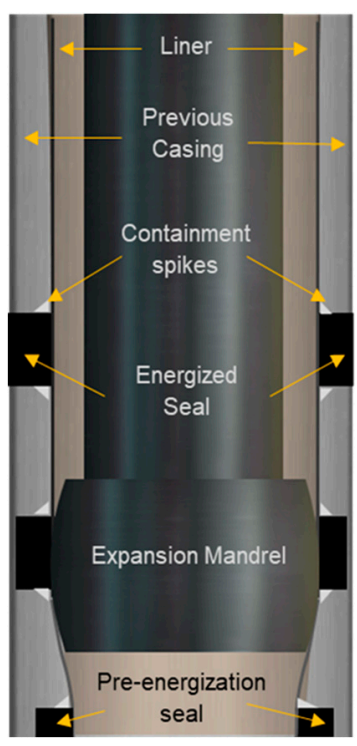

(b)

Figure 1. Schematic of (a) typical conventional and (b) expandable type hanger seal assemblies.

Failure in elastomer seal can compromise the well integrity and lead to a loss of well control (LOWC) event with health, safety, environment, and business consequences. An informal survey of Gulf of Mexico operators conducted by Lohoefer et al. [7] revealed that about $30 \%$ to $50 \%$ of the seals in liner-casing overlap fail. Another study indicated that up to $18 \%$ of offshore wells have some form of failure or weakness [8]. This problem has also been acknowledged by regulator Bureau of Safety and Environmental Enforcement (BSEE) in a recent investigation report of an incident [9]. Analysis of 156 LOWC events' data (2000-2015) [10,11] reveal that almost half $(46 \%)$ of the causes of secondary barrier failure are associated with seal or seal containing components of the well (Figure 2). A 2015 survey by Oil \& Gas iQ [12] puts seals as one of the top technical challenges (18\% of total) associated with High-Pressure High-Temperature (HPHT) oil and gas exploration.

Majority of the research related to elastomer seal and industry standards/guidelines have been focused on material composition, properties evaluation, and qualification $[11,13]$. Elastomer seal failure in the form of physical and chemical degradation such as rapid gas decompression, extrusion, compression set, abrasion, volumetric swelling, etc., is widely studied [11,14-16]. However, very limited information is available on function aspects of elastomer seal assemblies. Particularly, major research gaps are: the effect of seal energization method, the impact of energization failure, the consequence of failure in supporting components, and the effect of low quality energization. This 
paper attempts to fill one of these knowledge gaps by performing detailed comparison of conventional versus expandable type energization method.

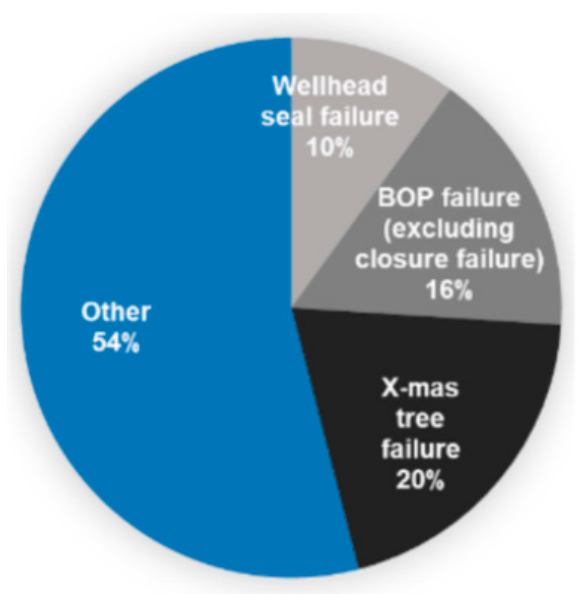

Figure 2. Causes of secondary barrier failure in 156 loss of well control events occurred during 2000-2015.

\section{Literature Review}

Commonly used elastomer material in the oil \& gas industry can be grouped into seven groups-NBR (Nitrile Butadiene Rubber), HNBR (Hydrogenated Nitrile Butadiene Rubber), EPDM (Ethylene Propylene Diene Monomer), FKM (Fluorocarbon), FEPM (Tetrafluoroethylene Propylene), FFKM (Perfluorocarbon), and PTFE (Polytetrafluoroethylen). The elastomer used are relatively stiffer and strain values are less, permitting assumption of linear elastic material behavior requiring only elastic modulus and Poisson's ratio [17]. For high deformations, use of hyperelastic material model such as neo-Hookean, Mooney-Rivlin, Ogden, Yeoh, and so forth, is needed. The hyperelastic material model requires various physical measurements like uniaxial, planer, biaxial stress behavior, and volumetric compression data.

The majority of relevant studies in the literature are focused on packer equipment, and to some extent, expandable tubular. Nonetheless, they provide useful information. Berger [18] performed physical tests on $7 \frac{3}{4}$-in. packer to assess different types of backup mechanisms such as steel foldback ring, mesh rings, and garter springs that support seal during energization process and maintains it under compression. Feng et al. [19] conducted 2D Finite Element Analysis (FEA) of axial compression in packer equipment with two elastomer components. They observed consistently higher contact pressure at the top elastomer element compared to bottom elastomer element. Alzebdeh et al. [20] studied the effect of seal length, thickness, and compression amount in 2D FEA model of expandable tubular sealing against different formations. Al-Kharusi et al. [21] and Al-Hiddabi et al. [22] conducted theoretical analysis of compression of elastomer seal in expandable tubular. Assuming linear elastic material properties, they presented analytical model to predict contact stress as a function of different amount of compression and differential fluid pressure across the seal.

Lin [23] used FEA to investigate structural integrity of slip element of packer. The author modelled different teeth spacing in slip and examined how it affects risk of failure. Ma et al. [24] used 2D FEA model of swelling elastomer packer element to investigate the effects of seal length, swelling amount, and different formation on seal quality and contact stress. They observed that in swellable elastomer packer equipment, contact stress profile peaks at the center of the element and declines towards both ends of the axial length. Wang et al. [25] studied elastomer failure modes such as extrusion, sliding, and rupture by conducting theoretical analysis supported by visual experimental observations. Zhong et al. [26] used FEA model of large bore expandable liner hanger to assess expansion force, cone pull out fore, contact stress at the seal-pipe interface, and deformations in hanger, casing, containment spikes, and cone body. 
Hu et al. [27] conducted 3D finite element analysis of compression packer equipment. They studied the effect of carbon black content in HNBR formulation and ranked the materials in terms of contact stress, shoulder extrusion, and stresses in structure of the packer. Elhard et al. [11] conducted extensive material properties measurement of commonly used oil and gas elastomer material and presented hyper-elastic models parameters. They also conducted experimental and finite element modelling study of O-ring extrusion. Recently, Patel et al. [13] used 3D finite element modelling to evaluate the performance of conventional liner hanger seal assembly. They conducted parametric study and ranked various design parameters based on the impact on seal performance. They also presented an empirical correlation to predict contact pressure.

\section{Objectives and Scope}

The objective of this paper was to compare seal energization and resultant contact stress profiles in conventional and expandable type hanger seal assembly.

For this purpose, three dimensional finite element model consisting of liner, elastomer seal, and casing elements was created. Both types of energization were simulated by manipulating boundary conditions. The simulations were performed at different amount of volumetric compressions. Comparison between both types of equipment was performed in terms of contact stress profile generated at the seal-pipe interface. For thorough comparison, investigation was conducted using both linear-elastic and hyper-elastic material models under frictionless and frictional surface conditions. For expandable hanger, configuration of containment spikes were also varied to examine its impact on contact stress profile. The commonly used FKM elastomer was employed as the reference material in the study.

\section{Finite Element Models}

Two dimensional schematic and top view of the both FEA models are shown in Figure 3. Dimensions of 18-in. liner and 20-in. casing were based on the actual well design where cement in liner-casing overlap likely failed [9]. The length of pipes were kept long enough to avoid any end-effects. Seal axial length was 2.5-in. and radial width was 0.6875 -in. To save number of mesh nodes used and minimize computational power, $1 / 16$ th of the model was used for the simulations.

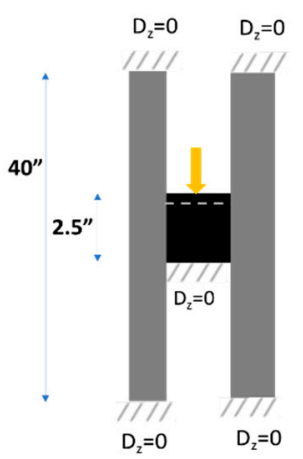

(a)

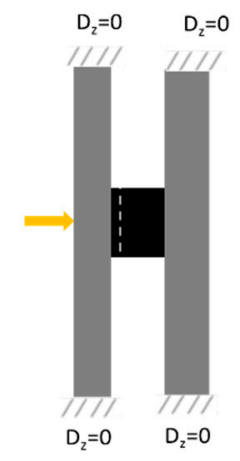

(b)

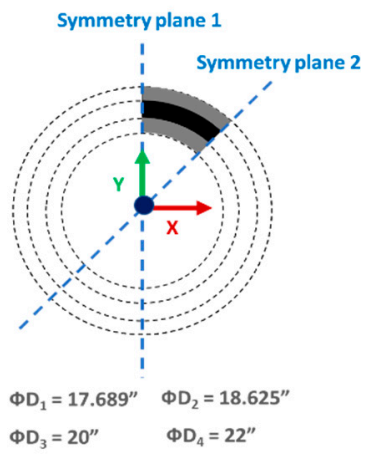

(c)

Figure 3. Two dimensional schematic of the Finite Element Analysis (FEA) models of (a) conventional and (b) expandable type hanger seal assembly, and (c) the top view.

Conventional seal energization was mimicked by applying zero displacement boundary conditions i.e., support at the bottom of elastomer element and compressing it from the top. To achieve compression, displacement type boundary condition was used. Displacement boundary condition was used instead of directly applying load because it provides faster and more controlled numerical convergence with less susceptibility to failure. Expandable hanger type seal energization 
was modelled by radially displacing the liner to compress annular seal element. Casing was fixed radial and axial during the energization process.

Liner and casing were modelled as isotropic linear elastic material. FKM elastomer was modelled as both linear elastic and hyper-elastic (Ogden 3rd order) material. Material properties of FKM were obtained from existing literature [11]. FKM is a common elastomer material used in the oil and gas applications because of its high resistance to chemical degradation [28]. The material properties for all three components are listed in Table 1. Hyper-elastic stress-strain behavior of FKM is graphically presented in Figure 4.

Table 1. Material properties used in the FEA model.

\begin{tabular}{cc}
\hline Material & Properties \\
\hline Linear elastic FKM at $73^{\circ} \mathrm{F}[11]$ & $\begin{array}{c}\text { Young's modulus }=310.5 \mathrm{psi} \\
\text { Poisson's ratio }=0.49\end{array}$ \\
\hline Hyper-elastic FKM at 73 ${ }^{\circ} \mathrm{F}[11]$ & Ogden 3rd Order \\
& $\mu_{1}=278 \mathrm{psi}, \mu_{1}=32.31 \mathrm{psi}, \mu_{1}=0.198 \mathrm{psi}$ \\
$\alpha_{1}=2.661, \alpha_{1}=-2.661, \alpha_{1}=10.79$ \\
Liner and casing & $\mathrm{D} 1=1.4 \times 10^{-5} \mathrm{psi}^{-1}, \mathrm{D}_{2}=2.7 \times 10^{-6} \mathrm{psi}^{-1}, \mathrm{D}_{1}=0$ \\
\hline & ${\text { Young's modulus }=29 \times 10^{6} \mathrm{psi}^{\prime}}^{\text {Poisson's ratio }=0.3}$ \\
\hline
\end{tabular}

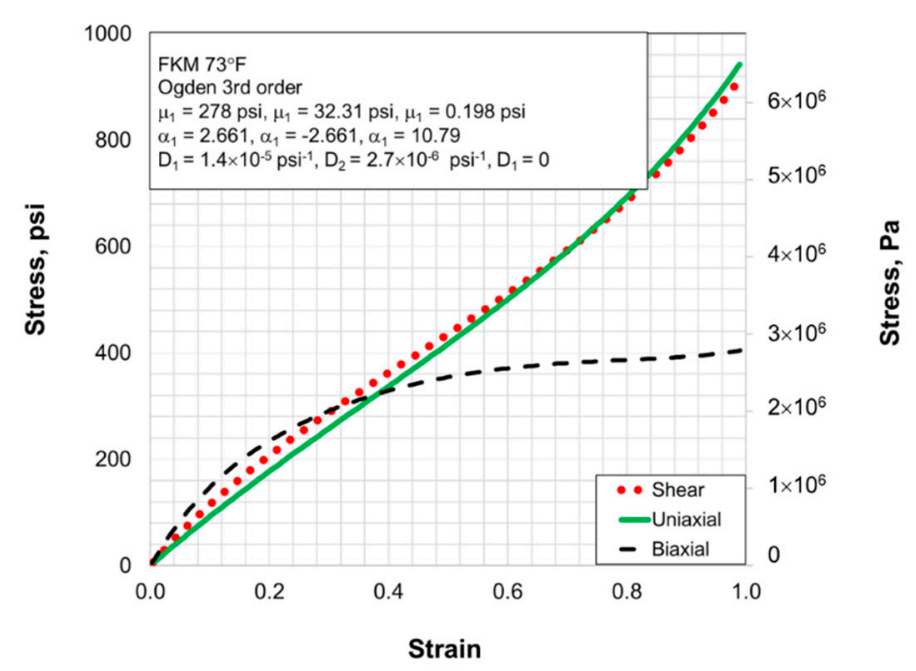

Figure 4. Uniaxial, shear, and biaxial material behavior of Fluorocarbon (FKM).

The model was discretized using hexahedral mesh because of its near orthogonality. Augmented Lagrange type contact formulation was used for representing seal-pipe contact interfaces. Stiffness factor was adjusted to achieve minimum possible penetration $\left(10^{-3}\right.$ to $10^{-4}$ inch) while still successfully achieving convergence.

Model verification was performed by ensuring that boundary conditions were being fulfilled and results were independent of symmetry plane selection and mesh size. Additionally, analytical validation was performed to ensure accuracy of the model predictions.

\section{Analytical Validation}

To validate the FEA model, the analytical relationship between bulk modulus, volumetric compression, and pressure can be used. As shown in the Figure 5, conventional hanger seal model is constrained in radial and axial direction after energization. The pressure generated at all four frictionless contacting surfaces should be same. This situation is similar to how bulk modulus is 
defined, i.e. application of equal external pressure over the surface of a three dimensional body to achieve bulk volumetric compression.

$$
\begin{gathered}
\frac{\Delta \mathrm{V}}{\mathrm{V}}=-\frac{\mathrm{P}}{\mathrm{K}} . \\
\mathrm{K}=\frac{\mathrm{E}}{3(1-2 v)}
\end{gathered}
$$

where $\mathrm{P}, \mathrm{K}$, and $v$ are pressure, bulk modulus, and Poisson's ratio, respectively. $\mathrm{V}$ is the original volume of elastomer seal, and $\Delta \mathrm{V}$ is change in volume as shown in Figure 5.

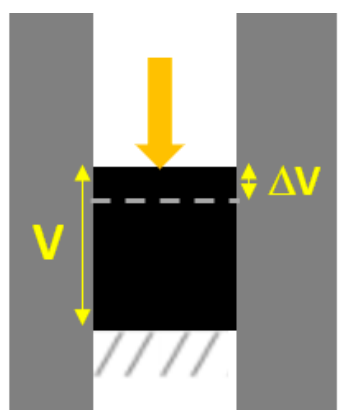

Figure 5. Volumetric compression in FEA model of conventional hanger seal.

Pressure calculated using Equation (1) were compared with FEA simulated contact pressure for different volumetric compression values. As shown in the Figure 6, a good match was obtained. Deviation from analytical calculation was $4 \%$ to $7 \%$ at lower ends of compression (less than $5 \%$ ) and less than $3 \%$ at higher ends of compression (more than $5 \%$ ).

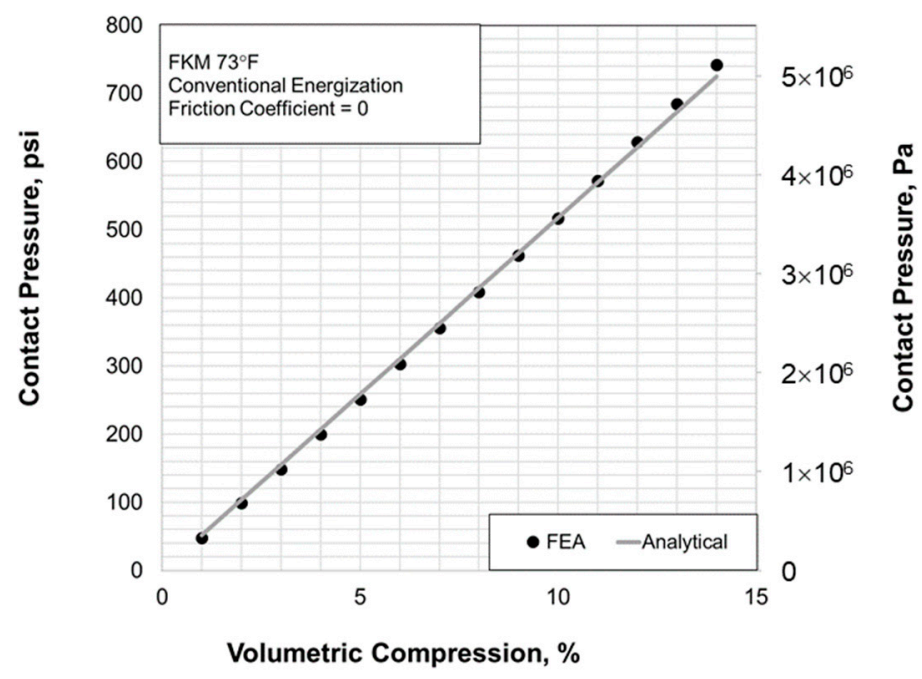

Figure 6. Comparison between contact stress simulated by FEA model and calculated using analytical equation.

\section{Simulation Results}

Five parameters were varied to run a total of 50 simulation cases. Factors investigated were energization method, amount of volumetric compression, friction coefficient, and material behavior. Results were grouped based on the individual parameters being examined.

\subsection{Effect of Energization Method}

Contact stress profiles generated in conventional and expandable liner hanger are presented in Figures 7 and 8 respectively. The profiles were generated at different volumetric compression 
using linear elastic FKM elastomer. Compression ratio defined as \% change in axial seal height (for conventional assembly) and \% change in seal inner radius (for expandable assembly) are also provided. Surface conditions were assumed to be frictionless. For expandable seal assembly, elastomer containment in axial direction was not considered.

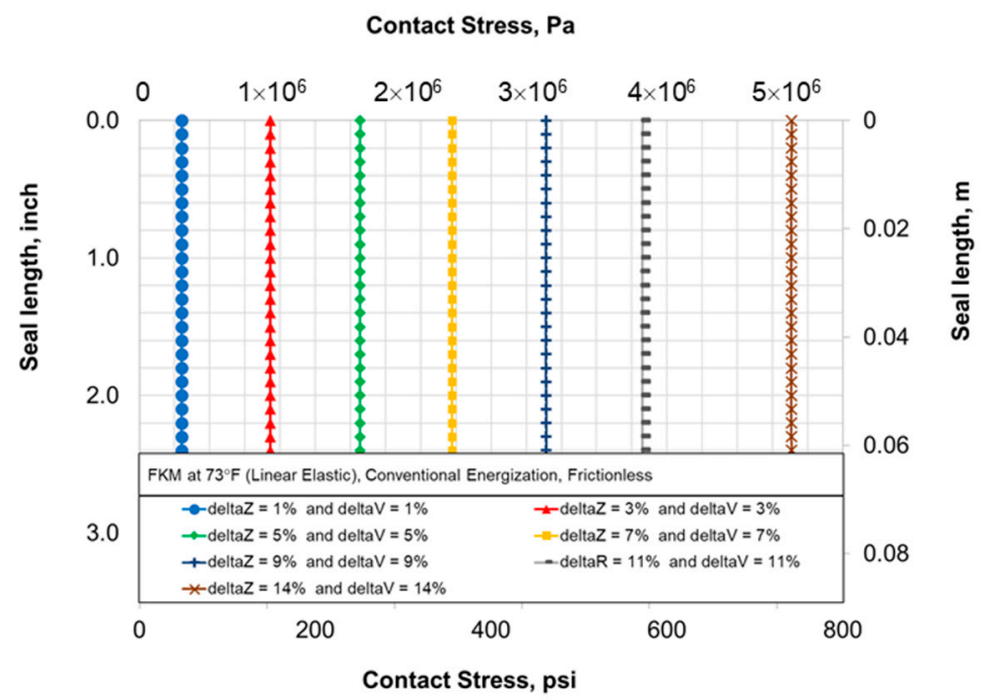

Figure 7. Contact stress profiles generated in conventional seal assembly at different volumetric compression.

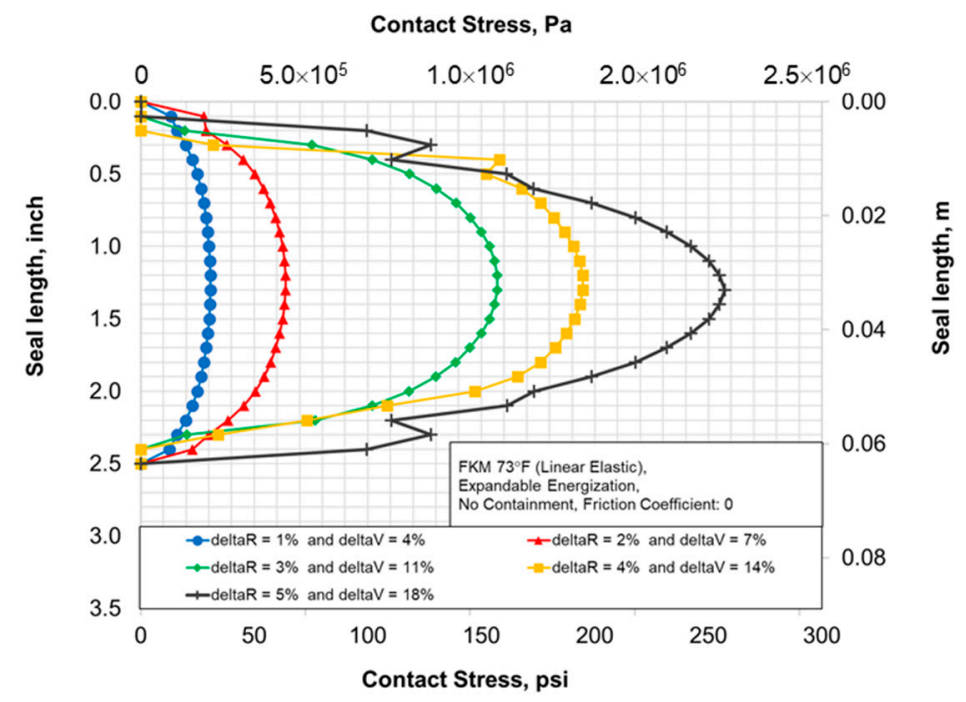

Figure 8. Contact stress profiles generate in expandable seal assembly at different volumetric compression.

As shown in the Figure 7, contact stress values remained constant along the seal length. This is because of the frictionless assumption for surface. For expandable liner hanger seal assembly (Figure 8), the contact stress peaked at the center of the seal and declines away from it. This is due to the fact that elastomer is not contained at the ends. Plus, seal-pipe interface is frictionless. Hence, the seal slides away from the center while being compressed; leading to peak contact stress at the middle and zero contact stress at the ends.

It is clear from the profiles that contact stress value increases with an increase in the amount of compression. The increment is practically linear for both of the seal assemblies as shown in the Figure 9. For the same amount of volumetric compression, conventional energization yields higher contact stress. For example, at $7 \%$ volumetric compression, conventional and expandable assembly 
generate 355 psi and 63 psi peak contact stress, respectively. This is expected because of the lack of elastomer containment in expandable seal assembly.

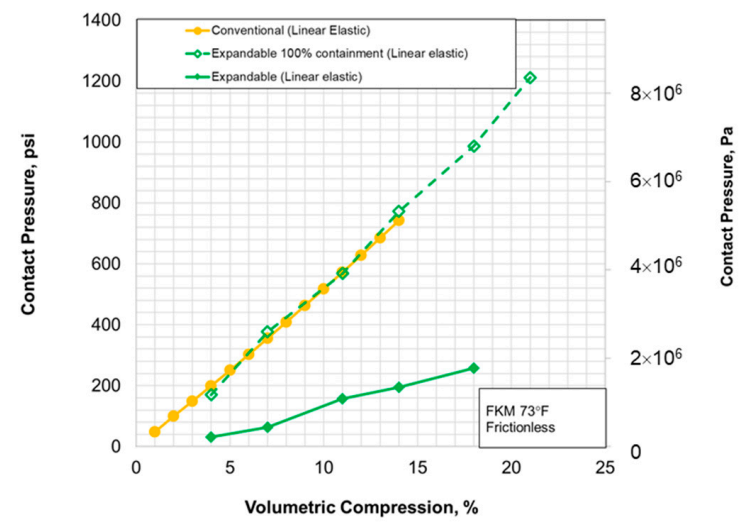

Figure 9. Contact pressure as a function of volumetric compression for conventional and expandable assembly (with and without elastomer containment).

Next, the effect of elastomer containment spikes was studied. Containment spikes were represented by zero displacement boundary conditions as shown in Figure 10. Five containment configurations were studied $-0,25,50,75$, and $100 \%$ containment. The configurations on either side were kept the same. Volumetric compression was kept constant at $4 \%$ and surfaces were considered frictionless.

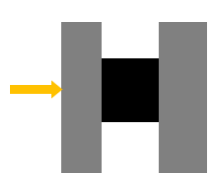

(a)

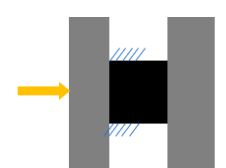

(b)

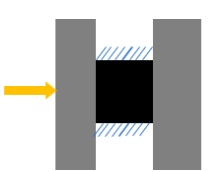

(c)

Figure 10. Elastomer seal containment in expandable liner hanger: (a) no containment, (b) 50\% containment, and (c) $100 \%$ containment.

It is clear from the results shown in Figure 11 that as elastomer containment increases, contact stress profile changes from parabolic to a progressively flatter one and eventually becomes constant at $100 \%$ containment. Peak contact stress values increases with increase in \% containment. The increment is not linear. At the same volumetric compression contact stress profile and values at $100 \%$ containment is same as in the conventional seal assembly (Figures 9 and 12).

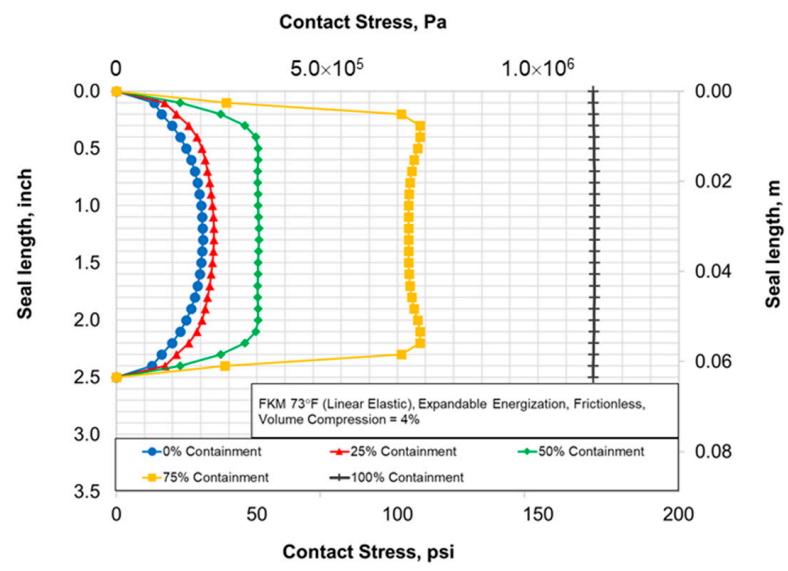

Figure 11. Contact stress profiles generated in expandable seal assembly at different amounts of seal containment. 


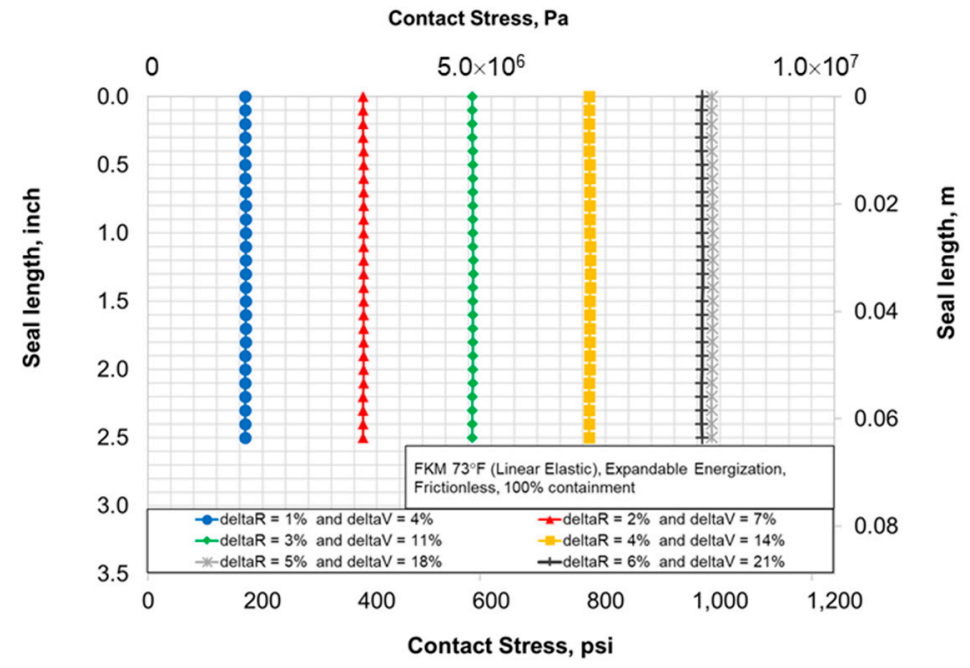

Figure 12. Contact stress profiles generate in expandable seal assembly with $100 \%$ containment and different volumetric compression.

\subsection{Effect of Material Behavior}

Next, the effect of material behavior was studied. Specifically, hyper-elastic material behavior of FKM (Ogden 3rd order) was modelled and resultant contact stress profiles were compared with the ones generated using linear-elastic material behavior. Contact stress profiles using the hyper-elastic FKM for conventional and expandable assembly without containment are presented in Figures 13 and 14 respectively.

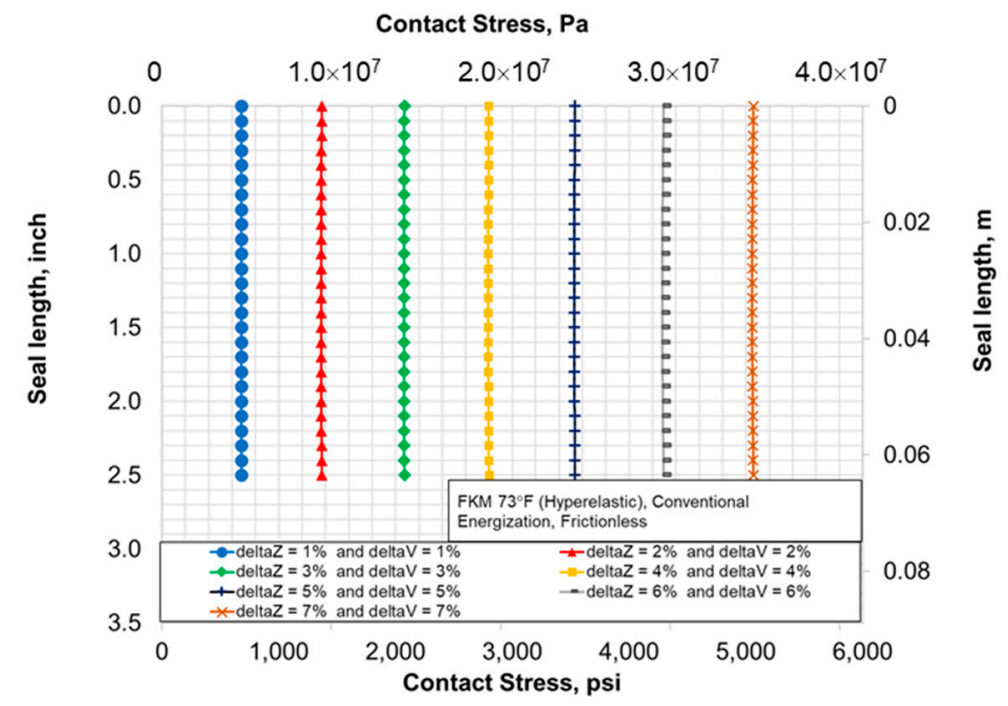

Figure 13. Contact stress profiles in conventional seal assembly for hyper-elastic FKM. 


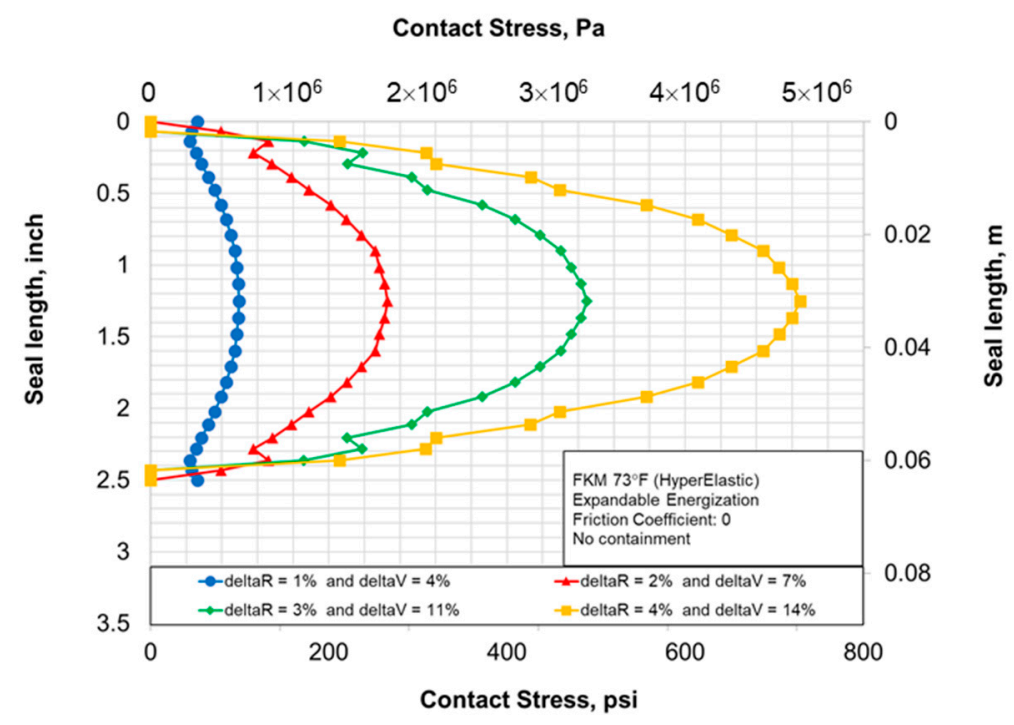

Figure 14. Contact stress profiles in expandable seal assembly for hyper-elastic FKM.

Results indicate that the contact stress profile in both assembly remains unchanged after switching to hyper-elastic material model. The contact stress values are notably higher than in the case of linear-elastic model (Figure 15). This is most likely due to the fact that in hyper-elastic model, elastomer material typically becomes stiffer at higher strain values and hence, at the same amount of deformation, higher contact stress is generated. As shown in the Figure 15, seal energization curve still remained practically linear with hyper-elastic material behavior.

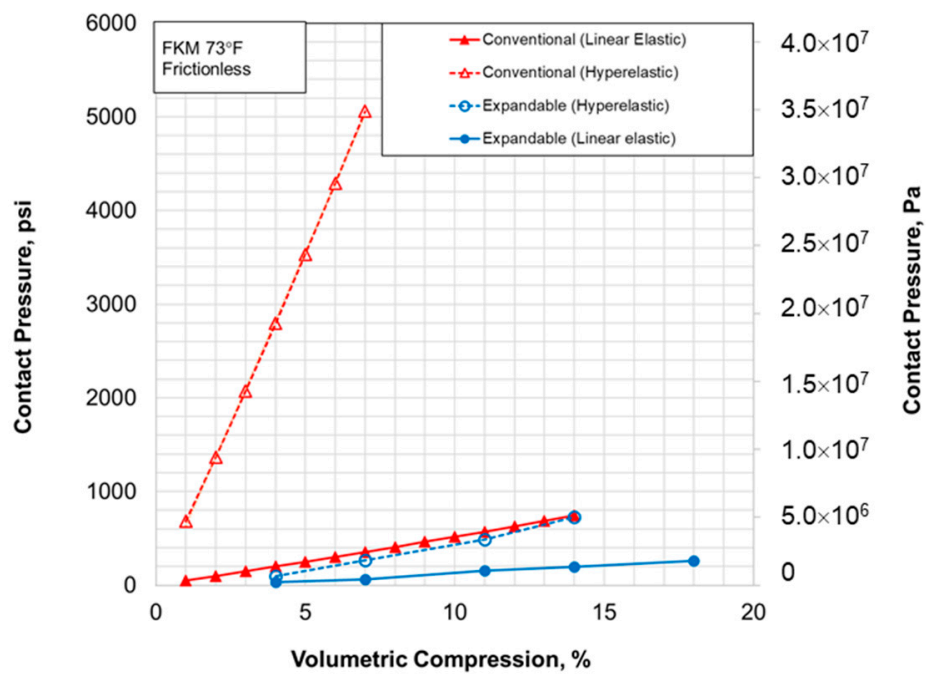

Figure 15. Contact pressure as a function of volumetric compression for conventional and expandable assembly with linear- and hyper-elastic material behavior.

\subsection{Effect of Friction}

All results discussed so far were generated assuming frictionless contact surface. Our next task was to investigate effect of friction on contact stress profiles generated in conventional and expandable seal assemblies. Typical friction coefficient between elastomer and steel tubing is 0.3 or higher [29].

Figure 16 presents contact stress profiles in conventional seal assembly assuming friction coefficient of 0.3 at elastomer-pipe interface. Frictionless contact stress profiles are also overlapped for easier comparison. In the presence of friction, contact stress profile is no longer constant. At the compression side of the seal, contact stress values are higher than the frictionless reference. Conversely, 
at the support side, contact pressure values are notably lesser than frictionless. It is clear that the compression or energization is not translated to the axially opposite end of the seal. The effect is more pronounced as volumetric compression increases. It can also be extrapolated that longer seal would also have more pronounced effect of friction. Failure to consider true frictional effect in conventional seal assembly design could be detrimental since significantly lower contact pressure values at the bottom of the seal can increase the risk of fluid penetration.

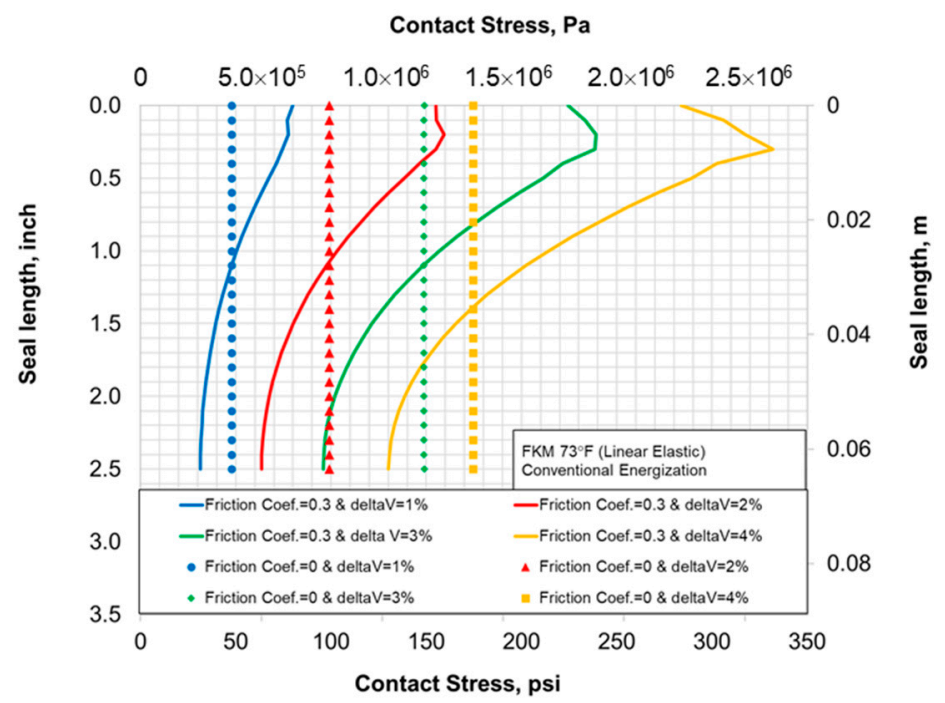

Figure 16. Effect of friction on contact stress profile in conventional seal assembly.

As shown in Figure 17, unlike conventional seal assembly, expandable assembly retained the overall shape of contact stress profile in presence of frictional sliding. However, the peak contact stress value increased with increase in friction coefficient from 0 to 0.3 to 0.6 .

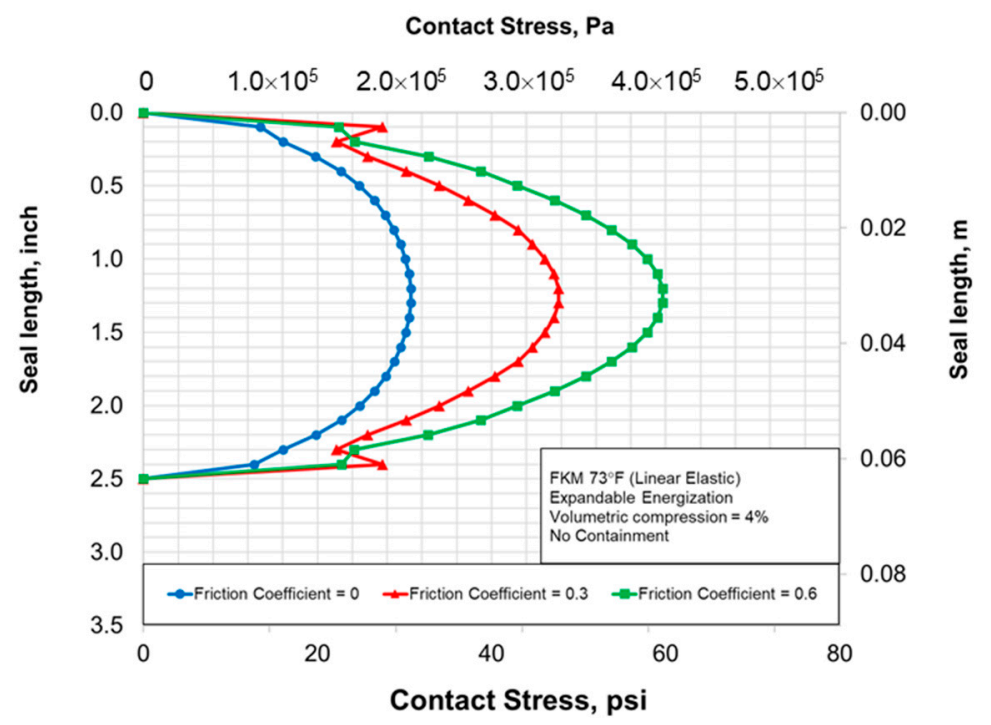

Figure 17. Effect of friction on contact stress profile in expandable seal assembly.

\section{Practical Implications}

For the same volumetric compression, conventional seal assembly yields higher contact pressure than expandable seal assembly without containment. At 100\% elastomer containment, contact stress profile in the expandable assembly matches with the conventional assembly. Actual expandable seal hanger assembly would almost always have elastomer containment spikes on either sides. However, to 
facilitate smooth running-in of the tool into the well, the spikes have to be shorter. This would provide less than $100 \%$ containment. Thus, in frictionless conditions, assuming that supporting components of either assemblies do not fail, conventional type energization will always yield higher contact pressure and should be preferred to the expandable type energization mechanism.

However, in the real field applications, contact surfaces are never frictionless. In presence of frictional stresses, contact stress profile of conventional seal assembly deviates from the uniform profile observed in frictionless condition (Figure 16). Moreover, the deviation is significantly dependent on amount of volumetric compression. Contact pressure peaks at a shorter distance from the compression side and declines rapidly towards the support side (Figure 16). Low contact pressure at the bottom would permit easy penetration of the fluid. On the other side, in expandable type energization, contact stress profile in frictional case maintains the same symmetry as the frictionless case (Figure 17). The profile becomes slightly narrower at the center but the contact pressure values at all locations are higher than the frictionless case. This improves the seal's performance. Although, peak contact pressure values are lesser than in the conventional energization, the difference would reduce with elastomer containment spikes. Overall, in presence of friction, expandable type energization is likely to be more reliable than the conventional energization because the former yields uniformly higher contact pressure than frictionless case while also maintaining the symmetry of the contact pressure profile.

Conventional seal assembly, in addition to the compression plates on either side, has moving parts like slips for supporting bottom plate and a mechanism to exert load on the top plate. Expandable seal assembly only has non-moving containment spikes on either side of the seal (Figure 1). If elastomer containment spikes in expandable assembly fail, the seal would still maintain contact pressure as shown in Figure 8. However, if slips or compression plates in conventional assembly fail, contact pressure and consequently sealability will be completely lost.

Expandable type seal energization also has additional design advantages over the conventional assembly. In expandable assembly, the seal is energized radially. Hence, it is possible to install multiple seal elements along the length of pipe and achieve same contact pressure in all of them. This redundancy further minimizes the risk of failure. In conventional assembly with multiple alternating seal elements and compression plates, because of the frictional stress being parallel to the compression load, it is not possible to achieve the same contact pressure in each seal. Based on the effect of friction shown in Figure 16, it can be inferred that the peak contact pressure would subsequently decrease from the top seal element to the bottom seal element. This effect of friction has also been demonstrated previously by Ma et al. [27] in simulations of dual rubber packer equipment.

As discussed in Section 6.2, selection of material model in modelling did not impact the shape of contact pressure profile in either of the seal assemblies. However, hyper-elastic FKM yielded higher contact pressure values than the linear elastic FKM. This is because of the fact that FKM material exhibited more stiffness at higher strain values. Thus, to prevent under-estimation or over-estimation of the seal's performance, it is important to measure the elastomer material behavior over the range of operating strains and use correct material model in predictions.

\section{Conclusions}

Using three dimensional finite element models, this study presents detailed comparison of seal energization in conventional and expandable liner hanger seal assemblies. The following are major conclusions from this work:

- In conventional seal assembly, contact stress value decreases along the seal length from the compression side towards the support side. In case of frictionless assumption, contact stress remains constant along the seal length.

- In expandable seal assembly, irrespective of friction coefficient, contact stress peaks at the center of the seal length and declines towards either sides of the axial ends. The profile becomes progressively flatter with increase in elastomer seal containment and becomes similar to conventional seal assembly at $100 \%$ containment. 
- Contact pressure values increases with increase in amount of compression, i.e., \%volumetric compression. The increment is practically linear, irrespective of energization method and material behavior.

- Selection of material model in modelling did not impact the shape of contact pressure profile in either of the seal assemblies. However, hyper-elastic FKM yielded higher contact pressure values than the linear elastic FKM. Therefore, it is important to measure the elastomer material behavior over the range of operating strains and use appropriate model in predictions.

- In frictionless condition, conventional type energization will almost always provide higher peak contact pressure values and should be preferred to the expandable type energization mechanism.

- In case of frictional contacts, expandable type energization is likely to be more reliable than the conventional energization because the former yields higher contact pressure than the frictionless case while also maintaining the symmetry of the contact pressure profile.

- Expandable energization is more robust to failure in supporting components than the conventional assembly. Even if both elastomer containment spikes completely fail, the expandable seal assembly would still maintain contact pressure.

- In expandable energization, it is possible to install multiple seal elements along the length of pipe and achieve same contact pressure in all elements. In conventional assembly with multiple alternating seals and compression plates, peak contact pressure would subsequently decrease from the top seal element to the bottom seal element.

Author Contributions: H.K.P. conceptualized the idea, developed FEA models, and ran simulations. S.S. provided guidance in data analysis and paper writeup.

Funding: Work was partially funded by Bureau of Safety and Environmental Enforcement (Project No: E17PC00005).

Acknowledgments: The authors would like to extend their sincere gratitude to the University of Oklahoma for providing necessary resources and granting the permission to publish this work.

Conflicts of Interest: The authors declare no conflict of interest.

\section{Nomenclature}

$\begin{array}{ll}\text { Acronyms } & \\ \text { BSEE } & \text { Bureau of Safety and Environmental Enforcement } \\ \text { EPDM } & \text { Ethylene Propylene Diene Monomer } \\ \text { FEPM } & \text { Tetrafluoroethylene Propylene } \\ \text { FFKM } & \text { Perfluorocarbon } \\ \text { FEA } & \text { Finite Element Analysis } \\ \text { FKM } & \text { Fluorocarbon } \\ \text { HPHT } & \text { High Pressure High Temperature } \\ \text { HNBR } & \text { Hydrogenated Nitrile } \\ \text { LOWC } & \text { Loss of Well Control } \\ \text { Symbols } & \\ \alpha_{\mathrm{i}} & \text { Ogden 3rd order material constant } \\ \text { deltaR } & \text { Percentage change in inner radius of seal } \\ \text { deltaV } & \text { Change in seal volume due to energization } \\ \text { deltaZ } & \text { Percentage change in axial seal height } \\ D_{\mathrm{i}} & \text { Ogden 3rd order material constant } \\ \mathrm{E} & \text { Elastic modulus / Young's modulus } \\ \mathrm{K} & \text { Bulk modulus } \\ \mu_{\mathrm{i}} & \text { Ogden 3rd order material constant } \\ v & \text { Poisson's ratio } \\ \mathrm{P} & \text { Contact pressure } \\ \mathrm{V} & \text { Initial seal volume } \\ \Delta \mathrm{V} & \text { Change in seal volume due to energization } \\ \end{array}$




\section{References}

1. Tu, B.; Cheng, H.L. Alternative Methodology for Elastomeric Seal RGD and Aging Testing Validates Long-Term Subsea Seal Performance and Integrity. In Proceedings of the Offshore Technology Conference, Houston, TX, USA, 2-5 May 2016. [CrossRef]

2. Patel, H.; Hariharan, H.; Bailey, G.; Jung, G. Advanced computer modelling for metal-to-metal seal in API flanges. In Proceedings of the SPE Annual Technical Conference and Exhibition, Dallas, TX, USA, 24-26 September 2018. [CrossRef]

3. Mullins, F. Metal-Formed Liner Hanger Avoids High-Setting-Pressure Requirements. J. Pet. Technol. 2016, 68, 4-8. [CrossRef]

4. Mccormick, J.; Matice, M.; Cramp, S. Big Bore Expandable Liner Hangers for Offshore and Deepwater Applications Reduces Cost and Increases Reliability: Global Case History. In Proceedings of the SPETT 2012 Energy Conference and Exhibition, Port-of-Spain, Trinidad, 11-13 June 2012. [CrossRef]

5. Walvekar, S.; Jackson, T. Development of an Expandable Liner-Hanger System to Improve Reliability of Liner Installations. In Proceedings of the Offshore Technology Conference, Houston, TX, USA, 30 April-3 May 2007. [CrossRef]

6. Smith, P.; Williford, J. Case Histories: Liner-Completion Difficulties Resolved With Expandable Liner-Top Technology. In Proceedings of the Canadian International Petroleum Conference, Calgary, AB, Canada, 13-15 June 2006. [CrossRef]

7. Lohoefer, C.L.; Mathis, B.; Brisco, D.; Waddell, K.; Ring, L.; York, P. Expandable liner hanger provides costeffective alternative solution. In Proceedings of the IADC/SPE Drilling Conference, New Orleans, LA, USA, 23-25 February 2000. [CrossRef]

8. Van Dort, R. Metal-to-metal seals meet downhole hazard demands. J. Pet. Technol. 2009, 61, 24-26. [CrossRef]

9. BSEE. QC-FIT Evaluation of Seal Assembly \& Cement Failures Interim Summary of Findings; Internal QC-FIT Report \#2014-02; Bureau of Safety and Environmental Enforcement: Washington, DC, USA, 2014.

10. Holand, P. Loss of Well Control Occurrence and 49 Size Estimators, Phase I and II; 51 Report \#ES201471/2; Bureau of Safety and Environmental Enforcement: Washington, DC, USA, 2017.

11. Elhard, J.D.; Duguid, A.; Heinrichs, M. Research on Safety Technology Verification for Materials and Pressure High Temperature (HPHT) Continental Shelf (OCS), High Corrosions in the U.S. Outer Material Evaluation. Technical Assessment Program Report (TAP 767AA) Prepared for Bureau of Safety and Environmental Enforcement. Available online: https:/ /www.bsee.gov/tap-technical-assessment-program/research-onsafety-technology-verification-for-materials-and (accessed on 15 September 2018).

12. Oil \& Gas iQ. High Pressure High Temperate, High Costs, High Stakes? 2015. Available online: https: //www.oilandgasiq.com/content-auto-download/5b04c1b543dfd0385d3c7c22 (accessed on 4 October 2018).

13. Patel, H.; Salehi, S.; Teodoriu, C.; Ahmed, R. Performance evaluation and parametric study of elastomer seal in conventional hanger assembly. J. Pet. Sci. Eng. 2019, 175, 246-254. [CrossRef]

14. Fernández, C.; Castaño, P. Compatibility Behavior of Elastomers for PCP Applications. 2016. Available online: https: / /www.onepetro.org/ conferencepaper/NACE-2016-7106 (accessed on 20 October 2018).

15. Cong, C.B.; Cui, C.C.; Meng, X.Y.; Lu, S.J.; Zhou, Q. Degradation of hydrogenated nitrile-butadiene rubber in aqueous solutions of $\mathrm{H}_{2} \mathrm{~S}$ or $\mathrm{HCl}$. Chem. Res. Chin. Univ. 2013, 29, 806-810. [CrossRef]

16. Campion, R.P.; Thomson, B.; Harris, J.A. Elastomers for Fluid Containment in Offshore Oil and Gas Production: Guidelines and Review. Research Report (RR 320) Prepared by MERL Ltd for the Health and Safety Executive, U.K. 2005. Available online: http://www.hse.gov.uk/research/rrpdf/rr320.pdf (accessed on 20 September 2018).

17. Bosma, M.G.R.; Cornelissen, E.K.; Schwing, A. Improved Experimental Characterization of Cement/Rubber Zonal Isolation Materials. In Proceedings of the SPE Asia Pacific Oil and Gas Conference and Exhibition, Brisbane, Australia, 16-18 October 2000. [CrossRef]

18. Berger, S. Experimental and Finite Element Analysis of High Pressure Packer Elements. Master's Thesis, MA Institute of Technology, Cambridge, MA, USA, September 2004.

19. Feng, D.; Yuan, Y.; Tan, B.; Yang, C.; Xu, G.; Wang, P. Finite Element Analysis of The Packer Rubbers on Sealing Process. In Proceedings of the 2010 International Conference on Mechanic Automation and Control Engineering, Wuhan, China, 26-28 June 2010. [CrossRef] 
20. Alzebdeh, K.; Pervez, T.; Qamar, S.Z. Finite Element Simulation of Compression of Elastomeric Seals in Open Hole Liners. J. Energy Resour. Technol. 2010, 132, 031002. [CrossRef]

21. Al-Kharusi, M.S.; Qamar, S.Z.; Pervez, T.; Akhtar, M. Non-Linear Model for Evaluation of Elastomer Seals Subjected to Differential Pressure. In Proceedings of the SPE/DGS Saudi Arabia Section Technical Symposium and Exhibition, Al-Khobar, Saudi Arabia, 15-18 May 2011. [CrossRef]

22. Al-Hiddabi, S.A.; Pervez, T.; Qamar, S.Z.; Al-Jahwari, F.K.; Marketz, F.; Al-Houqani, S.; van de Velden, M. Analytical model of elastomer seal performance in oil wells. Appl. Math. Model. 2015, 39, 2836-2848. [CrossRef]

23. Lin, Z.C. The strength analysis and structure optimization of packer slip based on ANSYS. Appl. Mech. Mater. 2013, 423, 1967-1971. [CrossRef]

24. Ma, M.; Jia, W.; Bu, Y.; Guo, S. Study on rubber seal design of a swellpacker in oil well cementing. Open Access Libr. J. 2014, 1, 1. [CrossRef]

25. Wang, Z.; Chen, C.; Liu, Q.; Lou, Y.; Suo, Z. Extrusion, slide, and rupture of an elastomeric seal. J. Mech. Phys. Solids 2017, 99, 289-303. [CrossRef]

26. Zhong, A.; Johnson, M.R.; Kohn, G.; Koons, B.; Saleh, M. Performance Evaluation of a Large Bore Expandable Liner Hanger for Field Operations in the Gulf of Mexico. In Proceedings of the Offshore Technology Conference, Houston, TX, USA, 4-7 May 2015. [CrossRef]

27. Hu, G.; Zhang, P.; Wang, G.; Zhang, M.; Li, M. The influence of rubber material on sealing performance of packing element in compression packer. J. Nat. Gas Sci. Eng. 2017, 38, 120-138. [CrossRef]

28. Salehi, S.; Ezeakacha, C.P.; Kwatia, G.; Ahmed, R.; Teodoriu, C. Performance verification of elastomer materials in corrosive gas and liquid conditions. Polym. Test. 2019, 75, 48-63. [CrossRef]

29. Ma, W.; Qu, B.; Guan, F. Effect of the friction coefficient for contact pressure of packer rubber. Proc. Inst. Mech. Eng. Part C J. Mech. Eng. Sci. 2014, 228, 2881-2887. [CrossRef]

(C) 2019 by the authors. Licensee MDPI, Basel, Switzerland. This article is an open access article distributed under the terms and conditions of the Creative Commons Attribution (CC BY) license (http:/ / creativecommons.org/licenses/by/4.0/). 